\title{
İş Yükü Fazlalığı Algısının Çalışan Performansı Üzerindeki Etkisinde İş Tatmininin Aracı Rolü: Sağlık Sektöründe Bir Uygulama
}

\author{
DOI: $10.26466 /$ opus. 878760
}

*

\author{
Fuat Korkmazer * \\ * Dr. Öğr. Üyesi, Muş Alparslan Üniversitesi \\ E-Posta: f.korkmazer@alparslan.edu.tr \\ ORCID: $\underline{0000-0002-2734-7309}$

\section{Öz}

Sağllk çalışanları uzun süreli çalışma, aşırı iş yükü, zaman baskısı, zor veya karmaşık görevler, yetersiz dinlenme araları ve fiziksel olarak kötü iş koşulları ile karşılaşmaktadırlar. Bu nedenle Sağllk çalışanlarının iş tatminini artırmak ve performansların yüksek seviyede tutmak zor olabilmektedir. $\mathrm{Bu}$ araştırmada iş yükü fazlalı̆̆ algısının çalışan performansı üzerindeki etkisinde iş tatmininin aracı rolünü araştırmak amaçlanmıştır. Veri toplamada İş Yükü Fazlalığı Ölçeği, Çalışan Performansı Ölçeği ve İş Tatmini Ölçeğginden yararlanılmıştır. Araştırma bir kamu hastanesinde çalışan 324 sağ lık çalışanına uygulanmıştır. Araştırmada elde edilen verilerin analizinde AMOS ve SPSS istatistik programlarından yararlanılmıştır. Araştırma sonucunda iş yükü fazlalığı algısının çalışan performansı üzerine etkisinde iş tatmininin aracılık rolünün olduğu görülmüştür. Ayrıca çalışanların iş yükü fazlalı̆̆̆, çalışan performansı ve iş tatminine ilişkin algılarının sosyo-demografik değişkenine göre farklılı gösterip göstermediği test edilmiştir.Yapılan analizlerde çalışanların yükü fazlalı̆̆ı, çalışan performansı ve iş tatminine ilişkin algılarının sosyo-demografik değiş̧kenlere göre farklilı gösterdiği tespit edilmiştir. Elde edilen bulgular doğrultusunda; işletme sahipleri ve yöneticilerin, çalışanlarının performansını ve iş tatminini yükseltmek için çalışanlara makul bir iş yükü tahsis etmeleri gerekmektedir.

Anahtar Kelimeler: Iş Yükü Fazlalığı, Çalışan Performansı, Iş Tatmini 


\title{
The Mediating Role of Job Satisfaction on the Effect of Workload Overview on the Employee Performance: An Implementation in the Health Sector
}

\begin{abstract}
Healthcare professionals are faced with long-term work, excessive workload, time pressure, difficult or complex tasks, insufficient rest breaks and physically bad work conditions. For this reason, it may be difficult to increase the job satisfaction of healthcare workers and to keep their performance at a high level. In this study, it was aimed to investigate the mediating role of job satisfaction in the effect of perception of excessive workload on employee performance. Workload Surplus Scale, Employee Performance Scale and Job Satisfaction Scale were used in data collection. The research was applied to 324 healthcare workers working in a public hospital. AMOS and SPSS 21 statistical programs were used to analyze the data obtained in the study. As a result of the research, it was seen that job satisfaction has a mediating role in the effect of the perception of workload on employee performance. In addition, it was tested whether the perceptions of employees regarding excessive workload, employee performance and job satisfaction differ according to the socio-demographic variable. In the analysis, it was determined that the perceptions of employees' burden, employee performance and job satisfaction differ according to socio-demographic variables. In line with the findings obtained; Business owners and managers are required to allocate a reasonable workload to employees in order to increase the performance and job satisfaction of their employees.
\end{abstract}

Keywords: Excessive Workload, Employee Performance, Job Satisfaction 


\section{Giriş}

İşletmeler arasında yaşanan rekabetin şiddeti gün geçtikçe artmakta, bunun sonucunda çalışma sürelerini etkin kullanma yoluyla verimlilik ve kârlılık artışını sağlama hususu daha da önem kazanmaktadır. Çalışan ile verilen görev arasında yaşanan uyumluluk çalışanın işini severek yaparak mesleği ile ilgili gelecek planı yapmasını sağlamaktadır. Aksi durumda uyumsuzluk söz konusu olduğunda çalışan strese girerek negatif yönde etkilenecektir. Böyle bir durumda çalışan kapasitesinin üzerine çıkamadığından, yoğun iş temposuna ayak uyduramamaktadır. Neticede, mutsuz olabilmekte ve enerjisi düşüp tükenebilmektedir (Ardıç ve Polatçı, 2009, s.26).

Gelişmiş toplumlarda teknoloji, ekonomi ve sosyal alanda yaşanan gelişmeler çalışma sürelerinin esnek olarak uygulanmasının sağlanması ihtiyacını doğurmuştur. Bu amaç doğrultusunda söz konusu ülkelerde çalışılmayan zamanın telafisi, yoğunlaştırılmış iş haftası, fazla çalışma karşılığının serbest zaman olarak verilmesi, kısa süreli çalışma gibi uygulamalar ortaya çıkmıştır. Bu toplumlar çalışma sürelerini azaltarak çalışma süresini daha esnek hale getirmiş iken, gelişmekte olan ya da az gelişmiş toplumlarda ise çalışma süreleri daha uzun olmaktadır. Ayrıca çalışma süreleriyle ilgili klasik yöntemler çalışma hayatında tamamıyla veya oldukça yaygın olarak kullanılmaktadır.

Günümüz rekabetçi ortamında, işletme sahipleri ile müşterilerin artan talep ve beklentileri sonucu ortaya çıkan aşırı iş yükü de performans düşüşüne kaynaklık eden etmenlerden birisi olarak tanımlanmaktadır. İş yükü fazlalığı algısının yüksek olması, çalışanların işlerinden duyduğu tatmini etkilemekte, işletmeler açısından önemli olan çalışan performansını olumsuz etkileyebilmektedir. Bunun yanında, teknoloji ve internet kullanımındaki yaygınlaşma, ürün ve hizmetlerde meydana gelen farklılaşma ve işletme stratejilerindeki sürekli değişim çalışanlar üzerinde aşırı iş yükünden kaynaklanan sorunların oluşmasına sebep olmaktadır.

Yapılan literature incelemesinde, iş yükü fazlalığının çalışanların performansları üzerindeki etkisinde iş tatmininin aracı etkisinin ölçüldüğü bir çalışmaya yazar tarafından rastlanmamıştır. Bu araştırma ile literatürdeki bu boşluklara katkı sağlanması düşünülmektedir. Bu çalışmada iş yükü fazlalığının çalışanların performansları üzerindeki etkisinde iş tatmininin aracı etkisini belirlemek amaçlanmıştır. Bu amaçla ilk önce iş yükü fazlalığı; 
çalışan performansı ve iş tatmini kavramları açılanmış, ardından kamuya bağlı bir hastanede gerçekleştirilen çalı̧manın bulgu ve sonuçlarına yer verilmiştir. Sonuç kısmında ise elde edilen bulgular doğrultusunda işletmelere önerilerde bulunulmuştur.

\section{İş Yükü Fazlalığı}

İş yükü, çalışanın normal mesai zamanı ve kabiliyetlerinin zıtlığında kapasitesinden daha çok görevden sorumlu olması olarak tanımlanabilir (Keser vd, 2017, s.57). İş yükü, bireye kişi başına ve birim zamana düşen iş nedeniyle baskı yapılması anlamına da gelmektedir. İş yükü, çalışan için oldukça önemli bir değişkendir. Yapılan çalışmalarda, bireyin ağır iş yükü koşullarında çalışması en temel tükenme sebeplerinden birisi olarak görülmüştür. Bir başka ifadeyle aşırı iş yükü, iş sebebiyle oluşan stresin en önemli ve en fazla rastlanan kaynaklarındandır (Karoshi, 2003, s.3).

Sağlığı elverişli olan bir çalışanın günlük çalışma enerjisi için bir limiti vardır. Bu limitinin üzerine çıktığında, yorgun düşerek, dikkatsiz ve işe odaklanamama gibi fiziksel sorunlar ile karşı karşıya kalacaktır. Fiziksel iş yükü, bir çalışanın performansının üzerinde harcadığı enerji miktarın ifade etmektedir. Zihinsel iş yükü ise hesaplama, iletişim kurma, hatırlama, araştırma, arama gibi faktörler ile alakalıdır. Zihinsel iş yüküne maruz kalan çalışanlarda stres, depresyon, kaygı, panik atak gibi kalp rahatsızlıkları ortaya çıkmaktadır. Yani çalışanın fiziksel iş yükü bedensel rahatsızlıklara neden olurken, zihinsel iş yükü psikolojik rahatsılılılara neden olabilmektedir (Bowling ve Kirkendall, 2012, s.221; İlçin, 2019, s.18-19 ). Çalışanlar, iş yükünden kaynaklı uzun saatler yoğun tempo ile birçok görevi yerine getirme sonucu bitkinlik ve stres yaşamaktadır. Yaşanan bu sıkıntı ve stres durumu da bedensel ve ruhsal enerjiyi negatif yönde etkilemektedir (Turgut, 2011:160). Bu durumun oluşturduğu yorgunluk, gerilim ve sıkıntı çalışanın iş tatminini olumsuz şekilde etkileyerek işinde performans düşüklüğüne sebep olacaktır.

İş yükü fazlalığı, bireyin normal zaman diliminde ve yetenekleri ile yapabileceğinden fazla bir işi yapmasının oluşturduğu zorunluluktur. İş yüküne yönelik algısal değerlendirmeler tipik olarak bir kişinin işinin nispi miktarına veya zorluğuna odaklanır. Bu nedenle, algılanan iş yükü, bir kişinin sahip olduğu işin miktarı veya subjektif bireysel standartlara göre ça- 
lışmasının zorluğu olarak düşünülebilir. İş yükü algısını etkileyen durumlar şunlardır (Bowling ve Kirkendall, 2012, s.225):

Kurumsal kısıtlamalar; örgütsel kısıtlamalar, iş ortamına müdahale eden yetersiz ekipman, yetersiz eğitim ve iş arkadaşlarının müdahalesi gibi unsurları içerisine almaktadır. Denetim Eksikliği; kötü niyetli denetleme, algılanan sözlü ve psikolojik saldırganlığı içermekte ve kötü denetim fiziksel unsurlar kapsamaktadır. Kötü niyetli denetim örnekleri arasında yöneticinin astlarına kaba davranması, astlarına yalan söylemesi ve astların gizliliğini ihlal etmesi gösterilebilir. Rol çatışması; bir çalışan birden fazla iş rolü üstlendiğinde ortaya çıkmaktadır. Rol çatışması, ağır bir iş yüküne sahip olunduğunda daha muhtemeldir, çünkü bir iş rolünü yerine getirmek için gereken zaman ve çaba, diğer iş rollerini yerine getirmek için gereken zaman ve çabadan çalmaktadır. Aslında, iş yükü bazen belirli bir rol çatışması biçimi olarak ele alınabilmektedir. İş-aile çatışması; kişinin çalışma hayatının talepleri ile aile hayatının talepleri uyuşmadığı durumlarda ortaya çımaktadır. Ağır iş yükü, iş-aile çatışmasına katkıda bulunabilir, çünkü iş görevlerine adanmış aşırı zaman ve kişisel enerji, çalışanın aile yükümlülüklerini yerine getirme kabiliyetini sınırlayabilir.

\section{İş Tatmini}

İş tatmini, iş ve çalışma ortamı ile ilgili olumlu ve olumsuz duygularla ilgilidir. Bir kişinin işinin veya deneyiminin değerlendirilmesinden kaynaklanan zevkli veya olumlu duygular olarak tanımlanmaktadır (Nelson ve Quick, 1995). Motivasyonu sağlanan ve iş tatminine ulaşan çalışanlar, yüksek moral sahibi olmakta bunun sonucunda da işletmelerine sağlayacakları faydaları artmaktadır. İş tatmini çalışanların verimliliğinde artış sağlarken iş tatminsizliği ise bu verimlilik ve performansta düşüşe sebebiyet vermektedir (Korkmazer ve Ekingen, 2017, s.463). Genel bir iş tatmini tanımı olmad1ğı için araştırmacılar çeşitli tanımlamalar yapmışlardır. Bu tanımlardan bazıları literatürde aşağıdaki tabloda gösterilmiştir.

Tablo 1. Literatürde Yapılmış Çeşitli İş Tatmini Tanımlan

\begin{tabular}{ll}
\hline Araşsırmacı & Tanımı \\
\hline Smith, Kendall ve Hulin (1969) & Çalışanın işe ilişkin duygularıdır. \\
\hline Locke (1969) & Çalşsanın başardığı zevktir. \\
\hline Lawler (1973) & Çalışanların beklentileri ile gerçek durum arasındaki farktır. \\
\hline Schultz (1982) & İsanları işe yönelik tutumları ve işlerine yönelik tutumlarıdır \\
\hline Davis (1998) & Çalışanları işlerinden memnun olmaları veya memnun olmamalarıdır. \\
\hline
\end{tabular}




\begin{tabular}{ll}
\hline Schermerhom (1994) & $\begin{array}{l}\text { İşle ilgili olumlu ya da olumsuz duyguların toplamı olan çalışanın tutumu } \\
\text { ile bu davranışların derecesidir. }\end{array}$ \\
\hline Şimşek (2003) & $\begin{array}{l}\text { Mali getirilerin yanı sıra iş tatmini, iş arkadaşları ile ilişkiler, fiziksel, } \\
\text { ruhsal sağlık ve çalışanın duyguları ile de bağlantılıdır. }\end{array}$ \\
\hline
\end{tabular}

(Öztürk, 2020, s.33)

İş tatmini boyutları üçe ayrılmaktadır. Bunlar (Weiss vd., 1967): içsel tatmin, dışsal memnuniyet ve genel memnuniyet olarak adlandırılmaktadır. İçsel tatmin; Tanınma, sorumluluk alma ve başarma arzusu gibi insanların içinden gelen durumlardır. Ücretler, denetim ve çalışma koşulları dışsal memnuniyet faktörleridir. Genel memnuniyet, hem içsel memnuniyeti hem de dişsal memnuniyeti içermektedir.

\section{Çalışan Performansı}

Performans, işletmenin tüm paydaşları için giderek daha önemli bir konu olmaktadır. Performans, işletmelerde belirlenmiş amaçların gerçekleştirilme derecesi şeklinde açıklanmaktadır. Başka bir ifadeyle performans, bir işi yapan birey, grup veya işletmenin o iş vasıtasıyla, belirlenen hedeflere göre ulaşabildiği yeri göstermektedir (Bayram, 2006, s.62). Bu tanımlamalar, çalışanların iş ile ilgili davranış, tutum ve iş verimliliği üzerinden yapılmaktadır. Ancak, insan gibi karmaşık ruhsal yapısı olan bir varlığı gerçek anlamda değerlemek oldukça zor ve zaman alan bir iştir.

Sağlık hizmetleri performansı ise, sağlık hizmetini güncel mesleki bilgi ve beceriler ile en uygun malzemeler kullanılarak, tam ve zamanında, doğru ve güvenilir bir şekilde tamamlanarak hastaya sunulması ve iletilmesidir (Tengilimoğlu, Işık ve Akbolat, 2012, s.387). Emeğin yoğun olduğu sağlık sektöründe çalışan sağlık çalışanlarının performanslarını arttırmak, sunulan hizmetin kalitesini yükseltmek, hasta memnuniyetini sağlamak ve örgütsel amaçlara ulaşmak için ciddi öneme sahiptir (Korkmazer, Ekingen ve Yıldız, 2016, s.273).

İş performansını etkileyen birçok davranışsal ya da örgütsel faktör bulunmaktadır. Çalışanların etkilendiği davranışsal faktörler (Mansi ve Yair, 2013, s.592): yönetici tutumları, çalışma arkadaşlarına yakınlık, çalışma arkadaşlarıyla işbirliği ve iletişimdir. Örgütsel faktörler ise (Rahman ve Badayai, 2010, s.488): iş yerinde gürültünün olması, sıcaklığın yüksek ya da düşük olması, havalandırmanın eksik olması, doğal ışığın eksik olması, çalışma alanının dar olması gibi faktörlerdir. 
Sağlık kurumlarında performans değerleme çalışmaları sonucunda elde edilen veriler yönetim tarafından verilecek kararlarda kullanılmaktadır. Ücret artışları, ikramiye ve primler, terfiler, eğitim, disiplin ve yönetime dair kararlar bu bilgiler doğrultusunda alınmaktadır (Erdoğan,1991, s.172). Sağlık hizmetleri açısından önemli performans ölçütleri (Aydın ve Demir 2006, s.31-33):

- Sağlık hizmetlerinden hasta memnuniyetinin sağlanması,

- Daha iyi bir sağlik düzeyine erişilmesi,

- Hizmet sunum süreci ölçümünün doğru yapılarak ödüllendirmesi

- Altyapı ve girdilerinin kalite ölçümünün yapılmasıdır

\section{Yöntem}

\section{Araştırma Amacı ve Hipotezleri}

Bu araştırma ile iş yükü fazlalığı algısının çalışan performansı üzerine etkisini ve iş tatminin aracılık rolünü belirlemek amaçlanmıştır. Bu amaç doğrultusunda oluşturulan araştırma modeli Şekil 1'de sunulmuş ve araştırma hipotezleri aşağıdaki gibi belirlenmiştir.

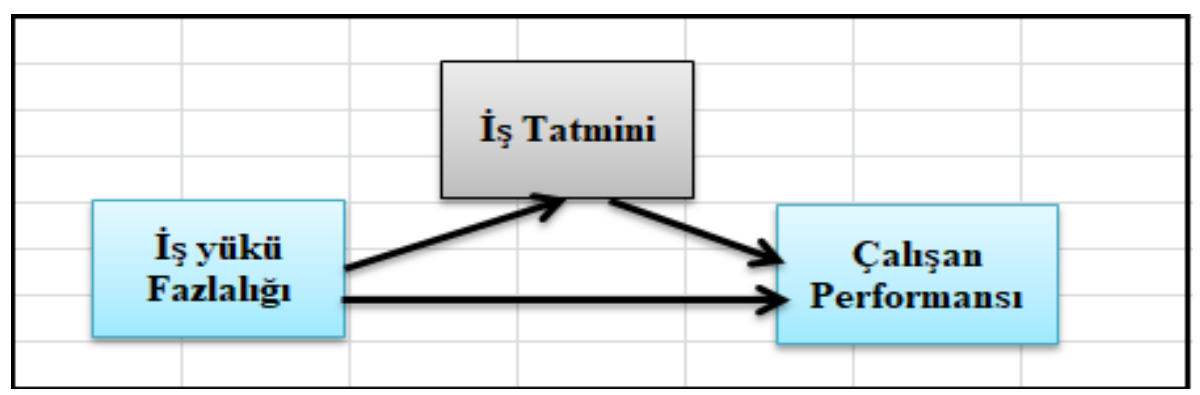

Şekil 1. Araştırma Modeli

Karasek (1979), İş Yükü-Kontrolü Teorisinde, çalışanların yaşadığı en önemli stres nedenlerinden biri olan iş yükü fazlalığının çalışanların kaygı düzeyini arttıracağını; artan kaygının ise iş tatmini ve çalışan performansı gibi olumsuz algıları etkileyeceğini belirtmiştir. Bu teori doğrultusunda, iş yükü fazlalığı nedeniyle, çalışanlar iş üzerindeki kişisel kontrollerini zayıflatan taleplerle karşılaştığında, olumsuz durumla başa çıkma mekanizması gereğince işlerine olan tatmini ve iş performansını düşüreceklerdir (De 
Croon vd., 2004; Jensen vd., 2013). Bu teoriden hareketle, iş yükü fazlalığının çalışan performansı üzerindeki etkisinde, iş tatmininin aracılık edebileceği değerlendirildiği için aşağıdaki hipotezler geliştirilmiştir:

- H1: İş yükü fazlalığı, çalışan performansını negatif ve anlamlı bir şekilde etkilemektedir.

- H2: İş yükü fazlalığı, iş tatminini negatif ve anlamlı bir şekilde etkilemektedir.

- H3: İş tatmini, çalışan performansını pozitif ve anlamlı bir şekilde etkilemektedir.

- H4: İş yükü fazlalığının çalışan performansı üzerinde iş tatminin aracılık etkisi vardır.

- H5: Kişisel-mesleki özelliklere göre, iş yükü fazlalı̆̆ı algıları farklılık göstermektedir.

- H6: Kişisel-mesleki özelliklere göre, çalışan performansı farklılık göstermektedir.

- H7: Kişisel-mesleki özelliklere göre, iş tatmini algıları farklılık göstermektedir.

\section{Evren, Örneklem ve Veri Toplama Araçlanı}

Araştırma evreni kamuya bağlı bir hastanede görev yapan sağlık çalışanlarından oluşmaktadır. Araştırmanın yapıldı̆̆ı hastane, Muş ilinde bulunan, bünyesinde temel tıp uzmanlık alanları olan ve özellikli birimlere (yoğun bakım, ameliyathane vb.) sahip genel hastane statüsünde bir hastanedir. Araştırmanın yapıldığı tarihte kurumda çalışan personel sayısı 986'dır. Araştırmada ayrıca örneklem seçilmeden, araştırmaya katılmayı kabul eden tüm sağlık çalışanları (324 kişi) araştırmaya dahil edilmiştir. Konu ile ilgili 29.12.2020 tarihi ile etik kurul kararı (Karar No: 27) ve sağlık bakanlığından yazılı izin alındıktan sonra internet üzerinden paylaşılarak cevaplar toplanmıştır. Eksiksiz doldurulan veriler istatistiksel değerlendirmeye alınmış ve veriler değerlendirilirken, frekans dağılımı, yüzdelik, t testi, Kruskal Wallis ve pearson korelasyon testlerinden yararlanılmıştır. Anketlerden elde edilen veriler SPSS veri tabanına aktarılarak SPSS ve AMOS programları ile istatistiki analizler yapılarak değerlendirmeye tabi tutulmuştur.

Verilerin toplanmasında kişisel bilgiler formu, iş yükü fazlalığı, iş tatmini ve çalışan performans ölçeklerinden yararlanılmıştır. Kişisel bilgiler formu, 
katılımcıların demografik bilgilerini içeren yaş, cinsiyet, medeni durum, eğitim durumu, meslekteki ve kurumdaki hizmet süresi, unvan durumu, çalıştığı birim ve çalışma şekli durumuna ilişkin 9 sorudan oluşmaktadır.

Çalışanların iş yükü fazlalığı düzeylerini tespit etmek için Imoisili (1985) tarafından geliştirilen ve Alam'ın (2016) Türkçeye uyarladığı 5 maddelik İş Yükü Fazlalığı Ölçeği kullanılmıştır. Ölçek tek bir boyuttan oluşmakta ve ölçek maddelerinin puanlandırılmasında 5'li likert ölçeğinden faydalanılmıştır. Alam'ın yaptığı Türkçeye uyarlama çalışmasında ölçeğin güvenilirlik katsayısının 0,780 olarak hesaplandığı, doğrulayıcı faktör analizi DFA uyum indekslerinin kabul edilebilir sınırlarda olduğu belirtilmiştir. Bu çalışmada iş yükü fazlalığı ölçeğine ait güvenirlik katsayısı (Cronbach alfa) 0,839 olarak hesaplamıştır.

Katılımcıların iş tatminini ölçmek için, Hackman ve Oldham (1975) tarafından geliştirilen, Şeşen (2010) tarafından Türkçe'ye uyarlanan İş Tatmin Ölçeği kullanılmıştır. Ölçek beş madden ve tek faktörden oluşmaktadır. Ölçeğin güvenirliği Şeşen (2010) tarafından yapılan çalışmada 0,880 olarak hesaplanmıştır. Ölçek maddelerinin puanlandırılmasında 5'li likert ölçeğinden faydalanılmıştır. Bu çalışmada İş tatmin ölçeğine ait güvenirlik katsayısı (Cronbach alfa) 0,760 olarak hesaplamıştır.

Çalışanların performanslarını ölçmek amacıyla 1999'da Kirkman ve Rosen, 2000 yılında Sigler ile Pearson tarafından yapılan çalışmalarda kullanılan 2008 yılında Türkçeye Çöl tarafından uyarlanan 4 maddelik İş gören Performans Ölçeğinden faydalanılmıştır. Ölçeğin güvenirliliğini değerlendirmek için hesaplanan Cronbach alpha değeri 0,94' tür. Bu çalışmada iş yükü fazlalığı ölçeğine ait güvenirlik katsayısı (Cronbach alfa) 0,680 olarak hesaplamıştır.

\section{Bulgular}

Katılımcıların mesleki-demografik bilgilerine ilişkin bilgiler Tablo 2'de verilmiştir. 
Tablo 2. Çalışanların Mesleki-Demografik Özellikleri

\begin{tabular}{|c|c|c|c|c|c|c|c|}
\hline & & $\mathrm{N}$ & $\%$ & & & $\mathrm{~N}$ & $\%$ \\
\hline \multirow{5}{*}{ Yaş } & $18-25$ & 77 & 23,8 & \multirow{2}{*}{ Cinsiyet } & Kadın & 144 & 44,4 \\
\hline & $26-30$ & 134 & 41,4 & & Erkek & 180 & 55,6 \\
\hline & $31-35$ & 62 & 19,1 & Medeni & Evli & 153 & 47,2 \\
\hline & $36-40$ & 26 & 8,0 & Durum & Bekâr & 171 & 52,8 \\
\hline & $41 \mathrm{ve}+$ & 25 & 7,7 & & & & \\
\hline \multirow{4}{*}{$\begin{array}{l}\text { Öğrenim } \\
\text { Durumu }\end{array}$} & Lise & 22 & 6,8 & \multirow{4}{*}{$\begin{array}{l}\text { Çalıştı̆̆ } 1 \\
\text { Birim }\end{array}$} & Poliklinik & 50 & 15,4 \\
\hline & Ön lisans & 64 & 19,8 & & Klinik & 58 & 17,9 \\
\hline & Lisans & 198 & 61,1 & & İdari birim & 82 & 25,3 \\
\hline & Lisansüstü & 40 & 12,3 & & Acil-Y.B.-Aml & 134 & 41,4 \\
\hline \multirow{4}{*}{$\begin{array}{l}\text { Meslekte } \\
\text { Çalışma } \\
\text { Süresi }\end{array}$} & 1 yıldan az & 17 & 5,2 & \multirow{4}{*}{$\begin{array}{l}\text { Kurumda } \\
\text { Çalışma } \\
\text { Süresi }\end{array}$} & 1 yıldan az & 34 & 10,5 \\
\hline & $1-5 \mathrm{yll}$ & 121 & 37,3 & & $1-5$ yil & 152 & 46,9 \\
\hline & $6-10$ yll & 123 & 38,0 & & $6-10$ yıl & 101 & 31,2 \\
\hline & $\begin{array}{l}11 \text { yıl } \\
\text { ve üstü }\end{array}$ & 63 & 19,4 & & 11 yıl ve üstü & 37 & 11,4 \\
\hline \multirow{3}{*}{$\begin{array}{l}\text { Unvan } \\
\text { Durumu }\end{array}$} & Tabip & 45 & 13,9 & \multirow{3}{*}{$\begin{array}{l}\text { Çalışma } \\
\text { Şekli }\end{array}$} & Gündüz & 77 & 23,8 \\
\hline & $\begin{array}{l}\text { Tabip Dışı } \\
\text { Sağ. Pers. }\end{array}$ & 217 & 67,0 & & Nöbet & 57 & 17,6 \\
\hline & İdari Pers. & 62 & 19,1 & & Gündüz+Nöbet & 190 & 58,6 \\
\hline TOPLAM & & 324 & 100 & TOPLAM & & 324 & 100 \\
\hline
\end{tabular}

Tablo 2’ de görüldüğü gibi katılımcıların yarısından fazlası $(\% 65,2) 30$ yaş altı sağlık çalışanlarından oluşmaktadır. Cinsiyet açısından incelendiğinde erkek katılımcıların çoğunlukta olduğu $(\% 55,6)$, eğitim durumuna bakıldığında en yüksek katılımı \%61,1 ile lisans mezunlarının oluşturduğu görülmektedir. Meslekte çalışma süresine bakıldığında, en fazla katılımı \%38 ile 6-10 yıl çalışanlar oluşturmakta, en az katılım ise \%5,2 ile 1 yıldan az süre ile çalışanlardan oluşmaktadır. Kurumda çalışma süresine bakıldığında, en yüksek katılımı \%46,9 ile 1-5 yıl çalışanlar oluşturmakta, en düşük katılım ise \%10,5 ile 1 yıldan az süre ile çalışanlardan oluşmaktadır. Ayrıca katılımcıların yarısından fazlası (\% 58,6) hem gündüz hem de nöbet şeklinde çalışanlardan oluşmaktadır.

\section{Geçerlik ve Güvenirliğe İlişkin Bulgular}

Anketin güvenirliği, iç tutarlılık katsayıları değerlendirilerek her ölçek için ayrıca hesaplanmıştır.

Tablo 3. Ölçeklerin ve Alt Boyutlarııın Güvenirlik Sonuçları

\begin{tabular}{lll}
\hline Ölçek & Madde Sayısı (n) & Cronbach $\alpha$ \\
\hline İş Yükü Fazlalığı & 5 &, 839 \\
\hline Çalışan Performansı & 4 &, 680 \\
\hline İş Tatmini & 5 &, 760 \\
\hline
\end{tabular}


Alpar (2014)'a göre anketin güvenilirliğinin test edilmesinde kullanılan Cronbach Alfa katsayısı 60-79 arasında olduğunda oldukça güvenilir, 80-100 arasında olduğunda ise ölçek yüksek güvenilir olarak kabul edilmektedir. İş yükü fazlalığ performansı ölçeğinde ise güvenirliğin en düşük $(=0,680)$ olduğu tespit edilmiştir. İş tatmini ölçeğinin ise güvenilirliğinin $(=0,760)$ olduğu tespit edilmiştir. Bu sonuçlar; iş yükü fazlalığ 1 ve iş tatmini ölçeklerinin yüksek derecede güvenilir olduğunu, çalışan performansı ölçeğinin ise oldukça güvenilir olduğunu göstermiştir.

Yapısal eşitlik modelinde öncelikle ölçme modeli (jenerik model) test edilmekte, modelde bir sorunun olmadığ1 görüldükten ya da sorunlar çözüldükten sonra da yapısal model test edilmektedir. Modelin test edilmesi neticesinde elde edilen uyum indeksleri modeliyle veri arasında uyum olduğunu gösterdiğinde, yapısal açıdan kurulan hipotezler kabul edilmekte; uyum indeksleri model ile veri arasında uyum olmadığını gösterdiğinde ise hipotezler reddedilmektedir (Meydan, Şeşen 2015, s.19-20). Ölçeklere ait Doğrulayıcı Faktör Analizinde (DFA), uyum indeks değerlerine göre programın önerdiği modifikasyon önerileri dikkate alınarak ölçeklere ait analizler tamamlanmıştır. İş yükü fazlalığı, iş tatmini ve çalışan performans ölçekleri için yapılan DFA analiz sonucuna göre ikişer madde programın önerdiği modifikasyon önerileri de dikkate alınarak birleştirilmiş ve ölçeğe son hali verilmiştir. Tüm ölçeklere ait uyum indeks değerleri kabul edilebilir ve iyi uyum değerleri arasında olduğu ve ölçeğe ait maddelerin faktör yükleri yeterli olduğu için ayrıca madde çıkarma işlemi yapılmamıştır.

Yapısal Eşitlik Modeli için uyum istatistikleri ile ilgili farklı parametreler kullanılmıştır. Kullanılması gereken parametrelerin hangisi olduğu ile ilgili bir fikir birliğine varılmasa da, birkaç parametrenin birlikte kullanılması önerilmektedir. Bu bağlamda, en az üç uyumluluk (Fit) test grubundan birer tanesi kullanılmalıdır. Bunlardan en sık kullanılanları (Chi-Square Goodness), GFI, AGFI, CFI, NFI, RMR ve RMSEA'dır (Meydan, Şeşen 2015, s.37). Yapısal eşitlik modellemesine ait uyum indeks değerleri Tablo 4 ' te verilmiştir. 
Tablo 4. Araştırma Modeli İçin DFA Sonuçları Uyum İndeksleri

\begin{tabular}{lllll}
\hline Uyum İndeksleri & Sonuç & İyi Uyum & Kabul Edilebilir & Açıklama \\
\hline$\chi 2 /$ sd & $\mathbf{2 , 5 8 7}$ & $<3$ & $<4-5$ & Iyi Uyum \\
\hline CFI & $\mathbf{9 5 6}$ & $>0.97$ & $>0.95$ & Kabul Edilebilir \\
\hline RMSEA & $\mathbf{0 7 0}$ & $<0.05$ & $0.06-0.08$ & Kabul Edilebilir \\
\hline GFI & $\mathbf{9 2 8}$ & $>0.90$ & $0.89-0.85$ & Iyi Uyum \\
\hline AGFI & $\mathbf{8 9 4}$ & $>0.90$ & $0.89-0.85$ & Kabul Edilebilir \\
\hline RMR & $\mathbf{0 6 2}$ & $<0.05$ & $0.06-0.08$ & Kabul Edilebilir \\
\hline
\end{tabular}

Tablo 4'e göre; modele ait uyum indeks değerleri incelendiğinde uyum indeks değerlerinin kabul edilebilir ve iyi uyum değerleri arasında olduğu görülmektedir. Oluşan bu sonuçlar modelin yeterli uyum sağladığını göstermektedir. Bu durumda iş yükü fazlalığının çalışan performansı üzerindeki etkisinde iş tatmininin kısmi aracılık rolünün olduğu söylenebilir.

\section{Değişkenler Arasındaki Korelasyonlar ve Regresyon Analizi Sonuçları}

Tablo 5. YEM ile Regresyon Analizi Sonuçları

\begin{tabular}{lllllll}
\hline Bağımlı & & Bağımsız & Estimate & S.E. & C.R. & P \\
\hline İş Tatmini & $<--$ & İş Yükü Fazlalığı &,- 365 &, 057 & $-6,395$ & ${ }^{* * *}$ \\
\hline Çalışan Performansı & $<--$ & İş Yükü Fazlalığı &,- 148 &, 047 & $-1,171$ & ${ }^{* * *}$ \\
\hline Çalısan Performansı & $<--$ & İş Tatmini &, 259 &, 074 & 3,511 & ${ }^{* * *}$ \\
\hline
\end{tabular}

Tablo 5'e göre; iş yükü fazlalığı; çalışan performansı ve iş tatminini negatif olarak anlamlı azaltmaktadır. İş tatmini de çalışan performansını anlamlı ve olumlu bir şekilde arttırmaktadır.

Tablo 6. Değişkenler Arasındaki Pearson Korelasyon Analizi

\begin{tabular}{llllll}
\hline & Ort. & S.S. & $\mathbf{1}$ & $\mathbf{2}$ & $\mathbf{3}$ \\
\hline 1. İş Yükü Fazlalığı & 3,80 &, 82 & 1,000 & & \\
2. Çalışan Performansı & 3,36 &, 71 &,$- 165^{* *}$ & 1,000 & \\
3. İş Tatmini & 2,56 &, 71 &,$- 422^{* *}$ &, $299^{* *}$ & 1,000 \\
\hline
\end{tabular}

Tablo 6'ya göre; İş yükü fazlalığı ile çalışan performansı arasında istatistiksel olarak anlaml, negatif ve düşük düzeyde (r: -165) bir ilişkinin olduğu görülmektedir $(\mathrm{p}<0,01)$. İş yükü fazlalığı ile iş tatmini arasında istatistiki olarak anlamlı, negatif ve orta düzeyde (r: -422) bir ilişkinin olduğu görülmektedir $(\mathrm{p}<0,01)$. İş tatmini ile çalışan performansı arasında da istatistiksel olarak anlamlı, pozitif ve düşük düzeyde (r: ,299 ) bir ilişki bulunmuştur $(\mathrm{p}<0,01)$. 


\section{Yapısal Eşitlik Modeline İlişkin Bulgular}

YEM'e ait uyum indeks değerleri ve programın önerdiği modifikasyon önerisi de dikkate alınarak model Şekil 2' deki son halini almıştır.

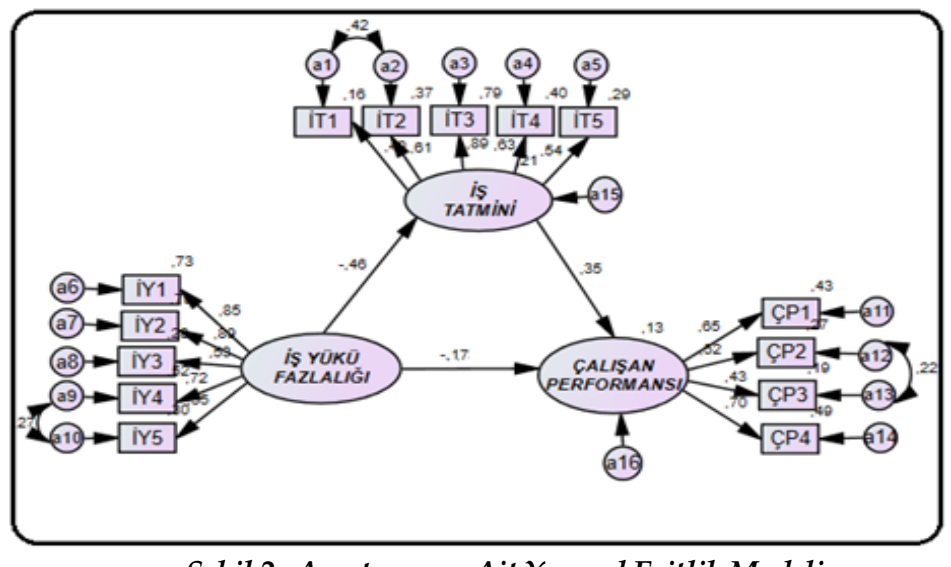

Şekil 2. Araştırmaya Ait Yapısal Eşitlik Modeli

Modelde, iş yükü fazlalığının çalışan performansı üzerinde iş tatminin aracılık rolü test edilmiştir. Aracılık rolünün ispatlanması için bazı koşullar sağlanmalıdır. Öncelikle bağımsız değişkenin bağımlı ve aracı değişken üzerine etkisi daha sonra aracı değişkenin bağımlı değişkene etkisi ayrı ayrı test edilir. Ardından araştırma modeline göre aracı değişken modele dahil edilir. Aracılık rolünden bahsedilebilmesi için bağımsız değişkenin, bağımlı değişken üzerindeki etkisinde düşme meydana gelirken, aracı değişkenin bağımsız değişken üzerinde anlamlı bir etkiye sahip olması gerekir (Baron ve Kenny 1986; Meydan ve Şeşen, 2015, s.130-131). İş yükü fazlalığı çalışan performansı üzerinde 0,17 birimlik doğrudan etkiye sahipken, iş tatmininin aracilık etmesi ile 0,16 birimlik dolaylı bir etkiye ve toplam 0,33 birimlik toplam etkiye sahip olduğu görülmektedir. Bu sonuçlar doğrultusunda iş yükü fazlalığı ile çalışan performansı ilişkisinde iş tatmininin aracılık rolüne sahip olduğu söylenebilir. Yapısal eşitlik modeli analiz sonuçlarına göre hipotezlerin durumu (0,05 anlamlılık düzeyinde) aşağıdaki gibidir.

- H1: “İş yükü fazlalığı, çalışan performansını negatif ve anlamlı bir şekilde etkilemektedir" hipotezi kabul edilmiştir.

- H2: "İş yükü fazlalığı, iş tatminini negatif ve anlamlı bir şekilde etkilemektedir" hipotezi kabul edilmiştir. 
- H3: "İş tatmini, çalışan performansını pozitif ve anlamlı bir şekilde etkilemektedir" hipotezi kabul edilmiştir.

- H4: "İş yükü fazlalığının çalışan performansı üzerinde iş tatminin aracılık etkisi vardır" hipotezi kabul edilmiştir.

Araştırmada ayrıca katılımcıların yaş, cinsiyet, medeni durum, eğitim durumu, meslekte çalışma süresi, kurumda çalışma süresi, çalışanın unvan bilgisi, çalıştığı birim ve çalışma şekli durumuna göre iş yükü fazlalığı; çalışan performansı ile iş tatmini düzeylerinde bir farklılık olup olmadığına da bakılmıştır.

Tablo 7. Sosyo-Demografik Grupların Ölçek Puanları Açısından Karşılaştırılması (n=324)

\begin{tabular}{|c|c|c|c|c|c|c|c|c|}
\hline & & & IYA & & ÇP & & İT & \\
\hline & & $\mathrm{N}$ & Mean & $\mathrm{P}$ & Mean & $\mathrm{P}$ & Mean & $\mathrm{P}$ \\
\hline \multirow{6}{*}{ Yaş } & $18-25$ & 77 & 183,82 & \multirow{6}{*}{, $009^{*}$} & 185,23 & \multirow{6}{*}{, $037^{*}$} & 146,10 & \multirow{6}{*}{, $025^{*}$} \\
\hline & $26-30$ & 134 & 142,88 & & 152,01 & & 168,44 & \\
\hline & $31-35$ & 62 & 164,85 & & 174,54 & & 174,65 & \\
\hline & $36-40$ & 26 & 197,27 & & 145,19 & & 190,54 & \\
\hline & 41 & 25 & 160,02 & & 136,82 & & 121,84 & \\
\hline & ve üstü & & & & & & & \\
\hline \multirow{5}{*}{$\begin{array}{l}\text { Öğrenim } \\
\text { Durumu }\end{array}$} & Lise & 22 & 143,61 & \multirow{5}{*}{, 556} & 214,95 & \multirow{5}{*}{, $015^{*}$} & 170,55 & \multirow{5}{*}{,961 } \\
\hline & Ön & 64 & 154,18 & & 143,02 & & 161,61 & \\
\hline & lisans & & & & & & & \\
\hline & Lisans & 198 & 165,17 & & 160,81 & & 161,06 & \\
\hline & Lisansüstü & 40 & 172,99 & & 173,21 & & 166,61 & \\
\hline \multirow{4}{*}{$\begin{array}{l}\text { Meslekte } \\
\text { Çalışma } \\
\text { Süresi }\end{array}$} & 1 yıldan az & 17 & 135,29 & \multirow{4}{*}{,028 } & 190,38 & \multirow{4}{*}{,257 } & 168,38 & \multirow{4}{*}{,078 } \\
\hline & $1-5$ yil & 121 & 163,94 & & 165,43 & & 178,98 & \\
\hline & $6-10 \mathrm{yll}$ & 123 & 150,55 & & 164,83 & & 148,90 & \\
\hline & 11 & 63 & 190,40 & & 144,80 & & 155,82 & \\
\hline \multirow{5}{*}{$\begin{array}{l}\text { Kurum } \\
\text { Çalışma } \\
\text { Süresi }\end{array}$} & 1 yıldan az & 34 & 148,38 & \multirow{5}{*}{,074 } & 153,72 & \multirow{5}{*}{ 731 } & 186,29 & \multirow{5}{*}{,280 } \\
\hline & $1-5$ yil & 152 & 152,82 & & 168,45 & & 165,21 & \\
\hline & $6-10 \mathrm{yll}$ & 101 & 182,22 & & 157,08 & & 151,32 & \\
\hline & 11 & 37 & 161,42 & & 160,91 & & 160,03 & \\
\hline & ve üstü & & & & & & & \\
\hline \multirow{3}{*}{ Unvan } & Tabip & 45 & 124,83 & \multirow{3}{*}{, $005^{*}$} & 158,50 & \multirow{3}{*}{,948 } & 205,36 & \multirow{3}{*}{, $004^{*}$} \\
\hline & Tabip Dışı & 217 & 172,79 & & 162,86 & & 155,75 & \\
\hline & İdari Pers. & 62 & 153,83 & & 164,15 & & 155,03 & \\
\hline \multirow{3}{*}{$\begin{array}{l}\text { Çalışma } \\
\text { Şekli }\end{array}$} & Gündüz & 77 & 139,29 & \multirow{3}{*}{, $000^{*}$} & 153,19 & \multirow{3}{*}{834} & 165,81 & \multirow{3}{*}{ 100 } \\
\hline & Nöbet & 57 & 222,05 & & 165,36 & & 156,87 & \\
\hline & Gündüz -Nö & 190 & 154,04 & & 174,38 & & 178,76 & \\
\hline \multirow{4}{*}{$\begin{array}{l}\text { Çalıştığ } 1 \\
\text { Birim }\end{array}$} & Poliklinik & 50 & 103,04 & \multirow{4}{*}{, $000^{*}$} & 158,96 & \multirow{4}{*}{,495 } & 195,18 & \multirow{4}{*}{, $047^{*}$} \\
\hline & Klinik & 58 & 205,97 & & 146,79 & & 151,91 & \\
\hline & İdari birim & 82 & 160,76 & & 166,70 & & 163,33 & \\
\hline & Acil AMLYB & 134 & 166,94 & & 168,05 & & 154,38 & \\
\hline
\end{tabular}

*p< 0,05; IYA: İş yükü fazlalığı, ÇP: Çalışan Performansı, İT: İş Tatmini 
Katılımcıların kişisel-mesleki özelliklerinin iş yükü fazlalığı algılarına etkilerinin incelendiği Kruskal Wallis testine göre; iş yükü fazlalığı algısının yaş, meslekte çalışma süresi, çalıştığı birim ve unvan grupları arasında anlamlı bir farkın olduğu; öğrenim durumu ve kurumda çalışma süresi grupları arasında ise anlamlı bir farkın olmadığı tespit edilmiştir. Farklılığın hangi gruptan kaynaklandığını tespit etmek için yapılan Post Hoc Dunnett T3 testi sonuçlarına göre; yaş açısından 18-25 yaş ve 26-30 yaş aralığından kaynaklandığı ve 18- 25 yaş aralığındaki sağlık çalışanlarının daha yüksek düzeyde iş yükü fazlalığ 1 algısına sahip olduğu tespit edilmiştir. Meslekte çalışma süresi açısından bakıldığında; 10 yıldan fazla olan sağlık çalışanlarının 1 yıldan az olanlara nazaran daha fazla olduğu tespit edilmiştir. Başka bir ifade ile çalışma süresi arttıkça iş yükü fazlalığı algısının da arttığı görülmektedir. Unvan açısından bakıldığında; Tabip dişı sağlık personeli ile tabip çalışanlar arasındaki farklılıktan kaynaklandığı ve tabip dışı sağlık personelinin tabiplerden daha yüksek düzeyde iş yükü fazlalığı algısına sahip olduğu tespit edilmiştir. Çalışma şekli açısından bakıldığında; Nöbet usulü çalışanlar ile Gündüz normal mesai çalışanlar arasındaki ve nöbet ile gündüz-nöbet usulü çalışanlar arasındaki farklardan kaynaklandığı görülmektedir. Başka bir ifade ile nöbet usulü çalışanların iş yükü fazlalığı algısı en yüksek iken bunu gündüz-nöbet şeklinde çalışanlar takip etmekte en düşük algıya ise gündüz çalışanlar sahip olmaktadır. Çalışılan birim açısından bakıldığında ise; Acil, Ameliyathane ve Yoğun bakım çalışanları ile Poliklinik çalışanlarından ve Klinik (Servis) ile Poliklinik çalışanlarından ayrıca İdari birim ile poliklinik çalışanları arasındaki farktan kaynaklanmaktadır. Başka bir ifade ile iş yükü fazlalığı algısı en yüksek olan grup acil, ameliyathane ve yoğun bakım gibi özellikli birimlerde çalışanlar, en düşük olan grup ise poliklinik çalışanlarıdır. Bunu sırasıyla klinik (servis) çalışanları ile idari birim çalışanları takip etmektedir.

Katılımcıların kişisel-mesleki özelliklerinin çalışan performansı algılarına etkilerinin incelendiği Kruskal Wallis testine göre; yaş ve öğrenim durumu grupları arasında anlamlı bir farkın olduğu; çalışma şekli, çalıştığı birim, unvan, meslekte çalışma süresi ve kurumda çalışma süresi grupları arasında ise anlamlı bir farkın olmadığı tespit edilmiştir. Farklılığın hangi gruptan kaynaklandığını tespit etmek için yapılan Post Hoc Dunnett T3 testi sonuçlarına göre; öğrenim durumu açısından lise mezunu ve ön lisans ile lise 
mezunu ve lisans mezunu arasındaki farktan kaynaklanmaktadır. Ayrıca çalışan performansı en yüksek olan grup lise mezunları iken en düşük olan lisansüstü mezunlarıdır. Başka bir ifade ile öğrenim durumu yükseldikçe çalışan performansı düşmektedir. Yaş açısından bakıldığında 18-25 yaş ve 41 üstü yaş aralığından kaynaklandığı ve 18-25 yaş aralığındaki sağlık çalışanlarının 41 üstü yaş aralığındaki çalışanlara göre daha yüksek düzeyde çalışan performansı algısına sahip olduğu tespit edilmiştir.

Katılımcıların kişisel-mesleki özelliklerinin iş tatmini algılarına etkilerinin incelendiği Kruskal Wallis testine göre; yaş, unvan ve çalışılan birim grupları arasında anlamlı bir farkın olduğu; öğrenim durumu ve kurumda çalışma süresi, meslekte çalışma süresi ve çalışma şekli grupları arasında ise anlamlı bir farkın olmadığı tespit edilmiştir. Farklılığın hangi gruptan kaynaklandığını tespit etmek için yapılan Post Hoc Dunnett T3 testi sonuçlarına göre; yaş açısından 26-30 ve 41 üstü yaş aralığından kaynaklandığı ve 26-30 yaş aralığındaki sağlık çalışanlarının daha yüksek düzeyde iş tatmini algısına sahip olduğu tespit edilmiştir. Unvan açısından bakıldığında; Tabipler ile tabip dışı sağlık personeli arasındaki farklılıktan kaynaklandığı ve tabiplerin tabip dışı sağlık personelinden daha yüksek düzeyde iş tatmini algısına sahip olduğu tespit edilmiştir. En düşük iş tatmini algısına ise idari personelin sahip olduğu tespit edilmiştir. Çalışılan birim açısından bakıldığında; Poliklinik çalışanları ve klinik (servis) çalışanları arasındaki farktan kaynaklanmaktadır. Başka bir ifade ile poliklinik çalışanları klinik (servis) çalışanlarına göre daha yüksek iş tatminine sahiptir.

Tablo 8. Cinsiyet ve Medeni Durum Gruplarının Ölçek Puanları Açısından Karşılaştırulmasi $(n=324)$

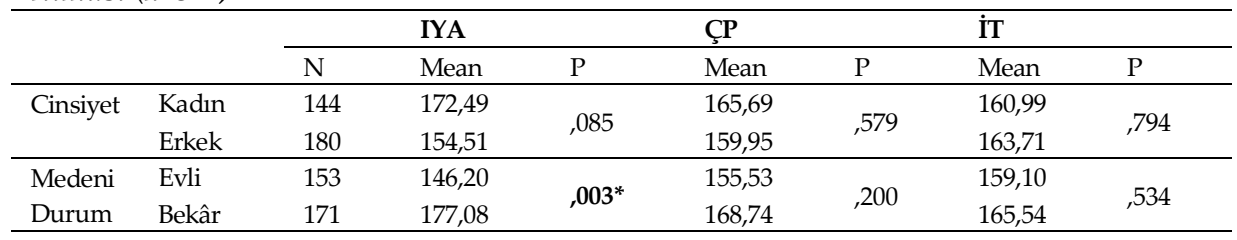

${ }^{*} \mathrm{p}<0,05$; IYA: İş yükü fazlalı̆̆ı, ÇP: Çalışan Performansı, İT: İş Tatmini

Katılımcıların kişisel-mesleki özelliklerinin iş yükü fazlalığı algılarına etkilerinin incelendiği Mann Whitney testine göre; iş yükü fazlalığı algısının medeni durum grupları arasında anlamlı bir farkın olduğu; cinsiyet grupları arasında ise anlamlı bir farkın olmadığı tespit edilmiştir. Bu sonuçlara göre 
bekâr çalışanların evli çalışanlara göre daha yüksek iş yükü fazlalığı algısına sahip olduğu tespit edilmiştir.

Katılımcıların kişisel-mesleki özelliklerinin çalışan performansı ve iş tatmini algılarına etkilerinin incelendiği Mann Whitney testine göre; cinsiyet ve medeni durum grupları arasında anlamlı bir farkın olmadığ tespit edilmiştir.

Bu sonuçlara göre; hipotezlerin durumu (0,05 anlamlılık düzeyinde) aşağıdaki gibidir.

- H5: Kişisel-mesleki özelliklere göre iş yükü fazlalığı algıları farklılık göstermektedir hipotezi kısmen kabul edilmiştir.

- H6: Kişisel-mesleki özelliklere göre, çalışan performansı farklılık göstermektedir hipotezi kısmen kabul edilmiştir.

- H7: Kişisel-mesleki özelliklere göre, iş tatmini algıları farklılık göstermektedir hipotezi kismen kabul edilmiştir.

\section{Sonuç ve Öneriler}

Bu çalışmada iş yükü fazlalığı algısının çalışan performansı üzerine etkisi ve iş tatminin aracılık rolü araştırılmıştır. Araştırma sonucunda iş tatminin iş yükü fazlalığı algısının çalışan performansı üzerine etkisinde aracılık rolünün olduğu görülmüsşür. Emek yoğun hizmetler olan sağlık hizmetlerinde çalışanların iş tatmin düzeyleri ve iş yükü fazlalığı algısı çalışan performansı üzerinde önemli bir etkiye sahiptir. Sağlik hizmetlerinde hizmeti üretenler doğrudan çalışanlar olduğundan bu çalışmanın önemi artmaktadır. Sarıdiken ve Çınar (2021) sağlık sektöründe iş yükünün, çalışanların performansı ve bakımın kalitesini olumsuz yönde etkilemekle birlikte daha sonra hasta güvenliğini de etkileyeceğini belirtmiştir.

Araştırma sonucunda iş yükü fazlalığı algısının çalışan performansı üzerine etkisinde iş tatmininin aracılık rolünün olduğu görülmüştür. Ampirik çalışmalarda, araştırma değişkenleri olan iş yükü fazlalığı, iş tatmini ve çallşan performansı arasındaki ilişkiyi birlikte ele alan bir çalışmaya rastlanmasa da, bu bulgu Karasek (1979)'in geliştirdiği İş Yükü-Kontrolü Teorisi'nin “çalışanların yaşadığı en önemli stres nedenlerinden biri olan iş yükü fazlalığının çalışanların kaygı düzeyini arttıracağını; artan kaygının ise iş tatmini ve çalışan performansı gibi olumsuz algıları etkileyeceği" varsayımını doğrular niteliktedir. Bu teori doğrultusunda sağlık çalışanlarının iş yükünün 
makul sınırlarda olması ve iş tatminlerinin yeterli düzeyde olması, iş performanslarını arttırarak kaliteli hizmetleri üretme motivasyonlarına destek olacaktır.

Araştırma sonuçlarına göre iş yükü fazlalığı algısının çalışan performansını etkilediği ve negatif yönlü anlamlı bir ilişkinin olduğu görülmüştür. Yapılan literatür taramasında çalışan performansının psikolojik sermayeden (Erkuş ve Fındıklı, 2013; Öğüt ve Kaplan, 2015; Korkmazer vd., 2016: Korkmazer ve Ekingen, 2017; Karatepe vd., 2019; Çavmak ve Acar 2020), liderlik tarzından (Cheng vd., 2004; Chen vd., 2014; Aslan, 2015; Tekin, 2019; Yıldız ve Ekingen, 2020) etkilendiği görülmüştür.

Araştırma sonuçlarına göre iş yükü fazlalığı algısının iş tatminini etkilediği ve negatif yönlü anlamlı bir ilişkinin olduğu görülmüştür. Bu sonuç literatürde yapılan çalışma sonuçlarıyla (Swartz, 1999; Keser, 2006; Yaşan vd., 2008; Nübling vd., 2010; Ceylan vd., 2016; Başc1llar ve Taşci, 2018; Eroğlu, 2020) benzerlik göstermektedir.

Araştırma sonuçlarına göre iş tatmininin çalışan performansını etkilediği ve pozitif yönlü anlamlı bir ilişkinin olduğu görülmüştür. Bu sonuç literatürde yapılan çalışma sonuçlarıyla (Vroom,1964; Iafalldano ve Muchinsky, 1985; Judge vd., 2001; Judge ve Bono, 2001; Seligman, 2002; LePine vd., 2002; Fisher ve Noble, 2004; Patterson vd. 2004; Lyubomirski vd., 2005; Harrison vd., 2006; Fisher, 2010; Yaman, 2011; Uysal vd., 2012; Erselcan ve Özer, 2018) benzerlik göstermektedir.

Ayrıca katılımcıların kişisel-mesleki özelliklerinin yaş, meslekte çalışma süresi, çalıştığı birim ve unvan grupları arasında iş yükü fazlalığı algısının anlamlı bir farkı olduğu görülmüştür. Çalışan performansı algıları açısından yaş ve öğrenim durumu grupları arasında anlamlı bir farkın olduğu görülmüştür. İş tatmini algılarına göre; yaş, unvan ve çalışılan birim grupları arasında anlamlı bir farkın olduğu görülmüştür.

Literatürde yapılan tarama ve araştırma sonuçları doğrultusunda iş yükü fazlalığının çalışanlar ve işletmenin performans çıtıları üzerinde oldukça önemli bir etkiye sahip olduğu tespit edilmiştir. Araştırma sonucunda elde edilen bu bulgular işletme yöneticilerine önemli veriler sunmaktadır. Araştırma sonuçlarına göre işletme sahipleri ve yöneticiler, çalışanlarının performansını ve iş tatminini yükseltmek ve iş yükü fazlalığı algısını düşürmek için:

- Çalışanlara makul bir iş yükü tahsis edilmesi sağlanmalıdır. 
- Görevler, çalışanlara makul ölçüde beklenenleri aşmayacak şekilde tahsis edilmelidir.

- İş yükünü artıran gereksiz prosedürler ortadan kaldırılmalıdır.

- Bir çalışan işten ayrılırsa yerine başkasını yerleştirme ile ilgili takvim genellikle üç ay içinde hafifletilmelidir.

- Çalışanların iş performansını artırmak için iş yükü hakkaniyetli olarak dağıtılmalıdır.

- Hakkaniyetli bir personel planlaması yapabilmek için iş yükü analizleri yapılmalıdır.

Tüm bu önerilerle birlikte, çalışmanın ileride yapılacak çalışmalara da yol göstermesi beklenmektedir. Araştırma, sadece bir ildeki kamu hastanesindeki sağlık çalışanları üzerinde yapıldığından, diğer illerdeki sağlık çalışanları ve sağlık sektörü dışındaki sektörlere de uygulanması konunun gelişimine katkı sağlayacaktır. Araştırma sonuçlarını genelleyebilmek için, farklı sektörler ve farklı örneklem grupları üzerinde araştırmaların yapılmasında fayda görülmektedir. Bunun yanında, iş yükü fazlalığı, iş performansı ve iş tatmininin diğer değişkenlerle ilişkilerini araştırmak gelecekte yapılacak araştırmalar için önerilmektedir. 
EXTENDED ABSTRACT

\section{The Mediating Role of Job Satisfaction on the Effect of Workload Overview on the Employee Performance: An Implementation in the Health Sector}

Fuat Korkmazer

Muş Alparslan University

The intensity of the competition between enterprises is increasing day by day, as a result, it becomes more important to increase productivity and profitability through effective use of working hours. The harmony between the employee and the assigned task enables the employee to make a future plan related to his profession by doing his job lovingly. Otherwise, in case of non-compliance, the employee will be stressed and negatively affected. In such a case, as the employee cannot exceed his / her capacity, he / she cannot keep up with the busy pace of work. As a result, they may be unhappy and their energy may decrease and run out (Ardıç and Polatçı, 2009, p.26).

In today's competitive environment, excessive workload resulting from the increasing demands and expectations of business owners and customers is defined as one of the factors that cause performance decline. The high perception of excessive workload affects the satisfaction of employees with their jobs and can negatively affect employee performance, which is important for businesses. In addition, the widespread use of technology and internet, the differentiation in products and services, and the constant change in business strategies cause problems on employees due to excessive workload.

With this research, it was aimed to determine the effect of the perception of excessive workload on employee performance and the mediating role of job satisfaction. For this purpose, the following hypotheses have been developed:

- H1: Workload excess affects employee performance negatively and significantly. 
- H2: Excessive workload affects job satisfaction negatively and significantly.

- H3: Job satisfaction affects employee performance positively and significantly.

- H4: Workload has an intermediary effect of job satisfaction on employee performance.

The population of the research consists of healthcare professionals working in a public hospital. The number of personnel working in the institution at the time of the research is 986 . In the study, all healthcare professionals (324 people) who agreed to participate in the study were included in the study without choosing a sample. After obtaining the ethics committee decision (Decision No: 27) on 29.12.2020 and written permission from the Ministry of Health, the answers were collected by sharing on the internet. Completely filled data were taken into statistical evaluation and while evaluating the data, frequency distribution, percentage, $t$ test, Kruskal Wallis and Pearson correlation tests were used. The data obtained from the surveys were transferred to the SPSS database and evaluated by performing statistical analysis with SPSS and AMOS programs. Personal information form, excessive workload, job satisfaction and employee performance scales were used to collect the data.

More than half of the participants $(65.2 \%)$ are healthcare workers under the age of 30 . When examined in terms of gender, it is seen that male participants are in the majority $(55.6 \%)$, and when the educational status is examined, it is seen that undergraduate graduates have the highest participation with $61.1 \%$. When looking at the duration of work in the profession, the highest participation is 38\% with 6-10 years employees and the least participation is with $5.2 \%$ of those working for less than 1 year. When looking at the duration of employment in the organization, the highest participation is $46.9 \%$, with employees for $1-5$ years, while the lowest participation is $10.5 \%$, with employees working for less than 1 year. In addition, more than half of the participants (58.6\%) consisted of those who work both during the daytime and on shifts.

It was determined that the reliability coefficient of the workload excess scale was the highest $(=0.839)$, and the reliability coefficient was the lowest $(=0.680)$ in the employee performance scale. The reliability of the job satisfaction scale was found to be $(=0.760)$. These results; showed 
that the scales of workload overload and job satisfaction are highly reliable, and the employee performance scale is quite reliable. It is seen that the fit index values of the structural equation model are between acceptable and good fit values. These results show that the model has a sufficient fit. In this case, it can be said that job satisfaction has a partial mediating role in the effect of excess workload on employee performance. In addition, workload excess; It negatively significantly reduces employee performance and job satisfaction. Job satisfaction also increases employee performance significantly and positively. It is seen that there is a statistically significant, negative and low level (r: -165) relationship between excessive workload and employee performance $(p<0.01)$. It is seen that there is a statistically significant, negative and moderate (r: 422) relationship between excessive workload and job satisfaction ( $p$ $<0.01$ ). A statistically significant, positive and low level (r:, 299) relationship was found between job satisfaction and employee performance ( $\mathrm{p}$ $<0.01)$.

According to the results of the structural equation model analysis, the status of the hypotheses is as follows.

- H1: The hypothesis that "excessive workload affects employee performance negatively and significantly" is accepted.

- H2: The hypothesis that "excessive workload affects job satisfaction negatively and significantly" is accepted.

- H3: "Job satisfaction affects employee performance positively and significantly" hypothesis was accepted.

- H4: The hypothesis that "excessive workload has an intermediary effect on employee performance" is accepted.

In line with the results of the screening and researches in the literature, it has been determined that excessive workload has a significant effect on the performance output of the employees and the enterprise. These findings obtained as a result of the research provide important data to business managers. According to the results of the research, business owners and managers, in order to increase the performance and job satisfaction of their employees and to reduce the perception of workload excess:

- It should be ensured that a reasonable workload is allocated to employees. 
- Tasks should be assigned to employees in a way that does not exceed reasonably expected.

- Unnecessary procedures that increase the workload should be eliminated.

- If an employee leaves the job, the timetable for replacement should generally be relaxed within three months.

- Workload should be distributed equitably in order to increase the work performance of employees.

- Workload analysis should be done in order to make an equitable personnel planning.

With all these recommendations, the study is expected to guide future studies. Since the research was conducted only on healthcare workers in a public hospital in one province, its application to healthcare professionals in other provinces and sectors other than the health sector will contribute to the development of the subject. In order to generalize the research results, it is beneficial to conduct studies on different sectors and different sample groups. In addition, it is recommended for future research to investigate the relationship between workload overload, job performance and job satisfaction with other variables.

\section{Kaynakça / References}

Alam, M. A. (2016) Techno-stress and productivity: survey evidence from the aviation industry. Journal of Air Transport Management, 50(1), 62-70.

Alpar, R. (2014). Uygulamal istatistik ve geçerlilik-güvenilirlik. (3. Baskı), Detay Yayıncllk, Ankara.

Ardıç, K. ve Polatçı, S. (2009). Tükenmişlik sendromu ve madalyonun öbür yüzü: işle bütünleşme. Erciyes Üniversitesi İktisadi ve İdari Bilimler Fakültesi Dergisi, 32(1), 21-46.

Aslan, E. (2015). Paternalist liderliğin çalş̧an performansına etkisinde iş ahlakınn rolü. Yüksek Lisans Tezi, Beykent Üniversitesi, Ankara.

Aydın S, Demir, M. (2006). Sağhkta performans yönetimi-performansa dayah ek ödeme sistemi, Sağ̆lkta Dönüşüm Serisi-2. Ankara: Onur Matbaacıllk Ltd. Şti.

Baron, R. M., ve Kenny, D. A. (1986). The moderator-mediator variable distinction in social psychological research: Conceptual, strategic, and statistical considerations. Journal of Personality and Social Psychology, 51(6), 1173. 
Başclllar, M. ve Taşci, A. (2018). İş yükü ve iş tatmini arasındaki ilişki: sosyal hizmet uzmanları üzerine bir araştırma. IGUSABDER, 4, 330-344.

Bayram L. (2006) Geleneksel performans değerlendirme yöntemlerine yeni bir alternatif: 360 derece performans değerlendirme. Sayıştay Dergisi, 47-65.

Bowling, N.A. ve Kirkendall, C. (2012). Workload: a review of causes, consequences, and potential interventions. Contemporary Occupational Health Psychology, 221238.

Ceylan H, Gül N, Öksüz M. (2016). Sosyal çalışmacılarda iş doyumu ve tükenmişliğe etki eden faktörlerin sosyal hizmet alanlarına göre karşlaştırmalı incelenmesi. Yalova Sosyal Bilimler Dergisi. 6(11), 43-69.

Chen, X. P., Eberly, M. B., Chiang, T. J., Farh, J. L., ve Cheng, B. S. (2014). Affective trust in Chinese leaders: Linking paternalistic leadership to employee performance. Journal of Management, 40(3), 796-819.

Cheng, B. S., Chou, L. F., Wu, T. Y., Huang, M. P., ve Farh, J. L. (2004). Paternalistic leadership and subordinate responses: Establishing a leadership model in Chinese organizations. Asian Journal of Social Psychology, 7(1), 89-117.

Çavmak, D. ve Acar, F. (2020). Pozitif psikolojik sermaye ile performans algisı arasındaki ilişki: sağlık çalışanları üzerine bir araştırma. İş ve Insan Dergisi, 7(2), 203212.

Çöl, G. (2008). Algılanan güçlendirmenin işgören performansı üzerine etkileri. Doğuş Üniversitesi Dergisi, 9(1), 35-46.

De Croon, E. M., Slutter, J. K., Blonk, R. W., Broersen, J. P., ve Frıngs-Dresen, M. H. (2004). Stressful work, psychological job strain, and turnover: A 2-year prospective cohort study of truck drivers. Journal of Applied Psychology, 89(3), 442.

Erdoğan, İ. (1991). İşletmelerde personel seçimi ve başar değerlendirme teknikleri. İstanbul Üniversitesi İşletme Fakültesi Yayınları: İstanbul.

Erkuş A. ve Fındıklı M. (2013) Psikolojik sermayenin iş tatmini, iş performansı ve işten ayrılma niyeti üzerindeki etkisine yönelik bir araştırma. Journal of the School of Business Administration, 42(2), 302-318.

Eroğlu, A. (2020). İş yükünün işten ayrılma niyeti üzerine etkisinde iş tatmini ve kişiörgüt uyumunun aracllı rolü. İs ve İnsan Dergisi, 7 (2), 213-227

Erselcan, R. C. ve Özer, P. S. (2018). İş doyumunun performansa etkisinde mutluluğun aracilık rolü üzerine bir araştırma. Girişimcilik ve Kalkınma Dergisi. 13(2), 148165.

Fisher, C.D. (2010). Happines at work, International Journal of Management Reviews, 12 (4), 384-412. 
Fisher C.D. ve Noble, C. S. (2004). A Within-person examinationof correlates of performance and emotions while working. Human Performance, 17(2), 145-168.

Hackman, J., \& Oldman, G. R. (1975). Development of the job diagnostic survey. Journal of Applied Psychology. 60 (2), 159-170.

Harrison, D.A., Newman, D.A. ve Roth, P.L. (2006). How important are job attitudes? Meta-analytic comparisons of integrative behavioral outcomes and time sequences, Academy of Management Journal, 49, 305-325.

Iaffaldano, M.T. ve Muchisky, P.M. (1985). Job satisfaction and job performance: a meta- analysis. Psychological Bulletin. 97, 251-273.

İçin, E. (2019). İs yükkü ve yönetici desteğinin çalşmaya tutkunluk üzerindeki etkisi. Yüksek lisans Tezi, Bahçeşehir Üniversitesi, İstanbul.

İmoisili, OA. (1985). Task complexity, budget style of evaluating performance and managerial stress: an empirical investigation. Ph.D. dissertation. University of Pittsburgh

Jensen, J. M., Patel, P. C., ve Messersmith, J. G. (2013). High-performance work systems and job control: consequences for anxiety, role overload, and turnover intentions. Journal of Management, 39(6), 1699-1724.

Judge, T.A. ve Bono, J.E.,(2001). Releationship of core self-evaluations, traits- selfesteem, generalized self-efficacy, locus control, and emotional stability- with job satistaction and job performance:a meta- analysis. Journal of Applied Pscyhology, 86, 80-92.

Judge, T.A., Thorsen, C.J., Bono, J.E., ve Patton, G.K.(2001). The job satisfaction- job performance realitionship: a qualitative and quantitative review. Psycological Bulletin, 127, 376-407.

Karasek Jr, R. A. (1979). Job demands, job decision latitude, and mental strain: implications for job redesign. Administrative Science Quarterly, 24(2), 285-308.

Karatepe, H.K., Kuşçu, F.N. \& Karaman M. (2019). Psikolojik sermayenin bireysel performansa etkisi: hemşireler üzerinde bir araştırma. Anemon Muş Alparslan Üniversitesi Sosyal Bilimler Dergisi, 7,105-114.

Karosh, (2003). Reduce stress, workload and work time and improve work-life balance before it's too late, hot topics in collective bargaining issues. Public Servise for Alliance of Canada, 5, 1-19.

Keser, A. (2006). Çağrı merkezi çalışanlarında iş yükü düzeyi ile iş doyumu ilişkisinin araştırlması. Kocaeli Üniversitesi Sosyal Bilimler Enstitüsü Dergisi, 11(1), 100-119.

Keser, A. Bilir, B. ve Aytaç, S. (2017). Niceliksel iş yükü envanterinin geçerlik ve güvenirlik çalışması. "İ̧̧, Güç" Endüstri IIlişkileri ve İnsan Kaynaklan Dergisi, 19(2), 5574. 
Kirkman B. L. and Rosen B. (1999) Beyond self-management: antecedents and consequences of team empowerment. Academy of Management Journal. 42(1), 58-74.

Korkmazer, F., Ekingen E. ve Yıldız, A. (2016). Psikolojik sermayenin çalışan performansına etkisi: sağlık çalışanları üzerinde bir araştırma. Hacettepe Sağllk İdaresi Dergisi, 19(3), 271-281

Korkmazer, F., ve Ekingen E. (2017). Örgütsel yabancllaşmanın iş tatmini ile ilişkisi: sağlık sektöründe bir uygulama. The Journal of Academic Social Science Studies, (63), 459-470.

LePıne, J.A., Erez, A. ve Johnson D.E. (2002). The nature and dimensionality of organizational citizenship behaviour: a critical review and meta analysis. Journal of Applied Psychology, 87, 52-65.

Lydon, J., Pierce, T. ve O'regan, S., (1997). Coping with moral commitment to longdistance dating relationship. Journal of Personality and Social Psychology, 73, 104 113.

Lyubomirsky,S., King, L. ve Diener, E. (2005). The benefits of frequent positive affect:does happiness lead to success?. Psychological Bulletin, 131(6), 803-855.

Mansl, G. ve Yaur L. (2013). Do instant messaging interruptions help or hinder knowledge workers' task performance?. International Journal of Information Management, 33, 591-596.

Meydan, CH. ve Şeşen, H. (2015), Yapısal eşitlik modellemesi - AMOS Uygulamaları, Detay Yayıncilık, Ankara.

Nelson, D.L. ve Quick, J.C. (1995). Organizational behavior: foundations, realities and challenges. New York, West Company Press.

Nübling M, Vomstein M, Schmidt SG, Gregersen S., Dulon M. ve Nienhaus A. (2010). Psychosocial work load and stress in the geriatric care. BMC Public Health. 10(428), 1-12.

Ögüt, A. ve Kaplan, M. (2015). Sağlık sektöründe psikolojik sermayenin iş performansı üzerindeki etkisi. Sosyal Ekonomik Araştırmalar Dergisi, 30, 86-99.

Öztürk, S. B. (2020). The effect of leadership styles on job satısfaction with the mediatıng role of creatiznty. Yeditepe University Institute of Social Sciences.

Patterson, M., Warr, P. ve West, M. (2004). Organizational climate and company productivity: the role of employee affect and employee level. Journal of Occupational and Organizational Psychology, 77, 193-216.

Rahman, A. ve Badayal, A. (2012). Theoretical framework and analytical discussion on uncongenial physical workplace environment and job performance among workers in industrial sectors. Procedia-Social and Behavioral Sciences, 42, 486495. 
Sarıdiken ve Çınar (2021). Sağlık profesyonellerinin bireysel iş yükü algı düzeylerinin ölçülmesi: türkçe geçerlilik ve güvenilirlik çalışması. Sağlık ve Sosyal Refah Araştırmalan Dergisi, 3(1), 61-66.

Seligman, M.E.P. (2002). Authentic happiness: using the new positive psychology to realize your potential for lastingfulfilment. Free Press, New York.

Sigler T. H. ve Pearson, C. M. (2000) Creating an empowering culture: examining the relationship between organizational culture and perceptions of empowerment. Journal of Quality Management. 5(1), 27-52.

Şeşen, H. (2010). Adalet algısının tükenmişliğe etkisi: İş tatmininin aracı değişken rolünün yapısal eşitlik modeli ile testi. Sazunma Bilimleri Dergisi, 9(2), 67-90.

Tekin, E. (2019). Paternalist liderliğin iş tatmini ve çalışan performansına etkisi üzerine bir araşturma. Third Sector Social Economic Review, 54(1), 178-204.

Tengilimoğlu, D., Işık, O. ve Akbolat M. (2012). Sağ̆lk işletmeleri yönetimi. Ankara: Nobel Yayın Dağıtım.

Turgut, T. (2011). Çalışmaya tutkunluk: iş yükü, esnek çalışma saatleri, yönetici desteği ve iş-aile çatısması ile ilişkileri. Atatürk Üniversitesi İktisadi ve İdari Bilimler Dergisi, 25(3), 155-179.

Vroom, V.H. (1964). Work and motivation. Wiley, New York.

Weiss, D. J., Dawis, R. W., England, G. W. ve Lofquist, L. H. (1967). Manual for the minnesota satisfaction quesitionnaire. University of Minnesota.

Yaşan A, Eşsizoğlu A, Yalçın M, Özkan M. (2008). Bir üniversite hastanesinde çalı̧̧an araştrrma görevlilerinde iş memnuniyeti, anksiyete düzeyi ve ilişkili etmenler. Dicle Tip Dergisi, 35(4), 228-233.

Yıldız, A., Ekingen, E. (2020). Paternalistik liderliğin hizmet inovasyon davranışı üzerine etkisinin ve iş tatmininin aracllk rolünün yapısal eşitlik modellemesi ile test edilmesi, Işletme Araştırmalan Dergisi, 12 (3), 2916-2926.

\section{Kaynakça Bilgisi / Citation Information}

Korkmazer, F. (2021). İş yükü fazlalığı algısının çalışan performansı üzerindeki etkisinde iş tatmininin aracı rolü: Sağlık Sektöründe Bir Uygulama. OPUS-Uluslararası Toplum Araştırmaları Dergisi, 17(36), xx-xx. DOI: 10.26466/opus.876760 